\title{
Research on Spatial Distribution Characteristics of Electronic Information Industry in Beijing and Its Value Chain
}

\author{
Ming Li \\ JiLin Business And Technology College, ChangChun, China \\ 120857715@qq.com
}

\begin{abstract}
Keywords: Spatial Distribution, Regional Division of Labor Based on Value Chain, Electronic Information Industry, Beijin.
\end{abstract}

\begin{abstract}
As one of the leading sectors, electronic information industry in Beijing has relatively strong industrial strength and a great prospect. Through analysis on the distribution of main value chain links of electronic information industry and large-scale enterprises engaging in the industry, characteristics of electronic information industry in Beijing and spatial distribution of its value chain are summarized. According to research result, distribution of electronic information industry in Beijing shows an obvious trend of suburbanization, and main value chain links of large-scale electronic information enterprises also show an obvious trend of clustering. There is a clear trend of suburbanization in the aspect of production process, which shows a multi-center structure. Division of labor based on function and division of labor based on region are obviously presented in main clusters of electronic information industry in Beijing and main value chain links of large-scale electronic information enterprises respectively.
\end{abstract}

\section{Introduction}

After evolution and development for more than 20 years, the overall layout of high technology industries in large and medium-sized cities of China shows a trend of clustering in distribution: Such industries are mainly clustering in three regions including Beijing-Tianjin-Tangshan region, Yangtze River Delta and Pearl River Delta. As the dominant sector of high technology industries, electronic communication equipment manufacturing industry has showed a rhombohedral pattern with two levels of growth pole. The first growth pole is located in three regions, including Pearl River Delta, Bohai Bay Rim and Yangtze River Delta; the line formed by Sichuan and Hubei is gradually developing into the second growth pole in this industry. The clustering and changing trend of electronic communication equipment manufacturing industry in China presents an inverted u-shaped curve, and enterprises are mainly clustering in eastern coastal regions such as Guangdong, Jiangsu and Shanghai. Some scholars conducted special studies on the distribution of those high technology industries inside various cities and found out that the spatial clustering of them is evident. However, they show a trend of spreading and suburbanization. According to the law of evolution of spatial distribution pattern of high technology industries summarized by Wang Zheng and others, the first stage of clustering occurred in science and technology parks around universities; in the second stage, these industries spread gradually toward edge cities and towns specializing in such industries; in the third stage, the said edge cities and towns formed high technology industrial belt; in the fourth stage such industries were distributed in newly established high technology industry centers in edge cities and towns specializing in such industries. Result of researches conducted by Yuanfeng and others indicates that information and communication enterprises in Suzhou have been gradually spreading from the original urban areas to periphery of the city, based on which a distribution characteristic of clustering centered on the original urban area and development zones has been gradually formed, with the number of such enterprises progressively decreasing in edges of the city. Result of researches conducted by Bi Xiujing and others indicates that software industry in Shanghai shows an obvious characteristic of clustering; however, center of such clustering has been drifting from central urban area to suburban areas[1], and software enterprises presents a spatial distribution pattern of spreading in metropolitan area and re-clustering 
in science parks. Spatial distribution pattern of various value chain links of large-scale and multi-area electronic information enterprises in Beijing is analyzed in this research.

\section{Spatial Distribution and Division of Labor Based on Function of Electronic Information Industry in Beijing}

At present, people engaging in electronic information industries in Beijing are mainly distributed in the northwest and southeast plains of Beijing. From the perspective of district, $80 \%$ of them are distributed in Haidian District, Daxing District and Chaoyang District, among which Haidian District alone accommodates almost 60\% of them[2], and Daxing District and Chaoyang District also accommodate more than $10 \%$ of them. Specific to residential districts, the largest number of people engaging in electronic information industry are distributed in Shangdi Sub-district Office (accounting for $15.37 \%$ of the total number) and the $11.68 \%$ of them are distributed in Beijing Economic-Technological Development Area; among those sub-district offices which accommodate the largest number of people engaging in electronic information industry, Zhongguancun Sub-district Office, Haidian Sub-district Office, Beixiaguan Sub-district Office, Jiuxianqiao Sub-district Office, Huayuanlu Sub-district Office, Konggang Sub-district Office and Xueyuanlu Sub-district Office accommodate 8.38\% , 6.37\%, 5.01\%, 4.87\%, 3.84\%, 3.77\% and 3.77\% of the total respectively. Among those areas which accommodate the largest number of people engaging in electronic information industry, Xibeiwang Town, Chengnan Sub-district Office, Wangjing Sub-district Office, Zizhuyuan Sub-district Office, Xincun Sub-district Office, Ganjiakou Sub-district Office, Qinghuayuan Sub-district Office, Beitaipingzhuang Sub-district Office and Jianwai Sub-district Office accommodate 2.21\%, 2.13\%, 2.11\%, 2.02\%, 1.96\%, 1.87\%, 1.96\%, $1.56 \%$ and $1.50 \%$ of the total (as indicated in Figure 1). It is thus clear that the largest number of people engaging in electronic information industry are distributed in Zhongguancun in Haidian District-areas surrounding Shangdi and Yizhuang in Daxing District, followed by Jiuxianqiao-Wangjing Sub-district Office in Chaoyang District and Tianzhu Area in Shunyi District. In addition, a relatively large number of them are also distributed in Chengnan Sub-district Office in Changping District, Huaxiang Village in Fengtai District and Jianwai Street in Chaoyang District.

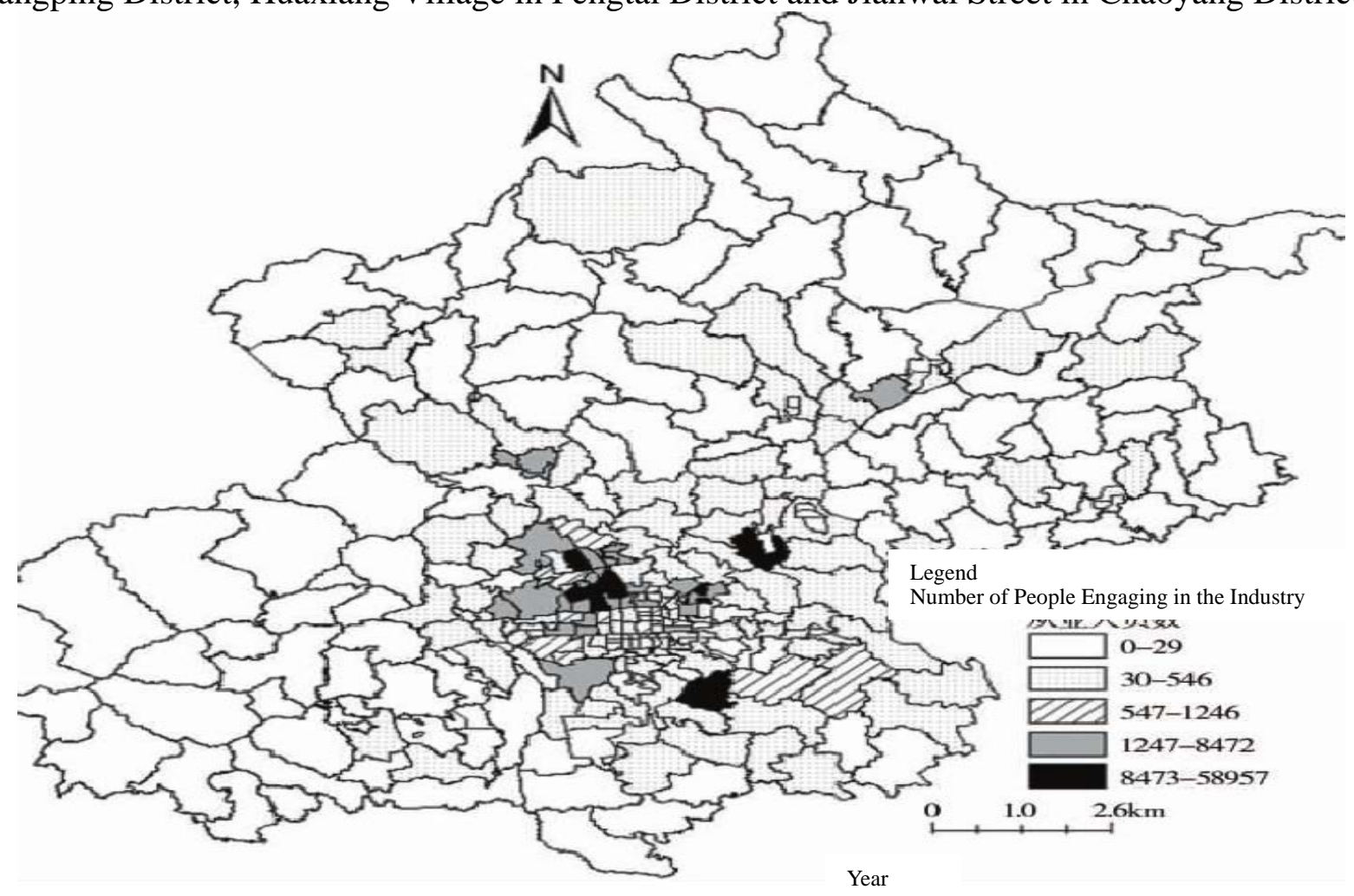

Fig. 1 The spatial distribution of electronic information industries in Beijing ( 2008 ) 


\section{Spatial Distribution of Main Value Chain Links of Large-scale Electronic Information Enterprises in Beijing}

The total number of institutions under 30 large-scale electronic information enterprises distributed in Beijing reaches 137, among which Zhongguancun Haidian Science Park accommodates most of them, accounting for $38 \%$ of the total, which is followed by Beijing Central Business District, Electronic Technology Park in Zhongguancun Science Park and Beijing Economic-Technological Development Area, respectively accounting for 18\%, 17\% and 13\%. 5\% and 3\% of them are also located in Beijing Tianzhu Airport Economic Development Zone and Zhongguancun Shijingshan Science Park. In addition, only 7\% of them are distributed in areas surrounding Dongchang'an Avenue, Xichang'an Avenue, Jinbao Street, Zizhuyuan and Xizhimen. From the perspective of main value chain links, there are largest number of R\&D sectors, which reaches 60 and accounts for $44 \%$ of the total, namely that each enterprise has two R\&D sectors located in Beijing in average. The numbers of sales and marketing sectors are 30 and 28 respectively, accounting for $22 \%$ and $20 \%$ of the total respectively, namely that each enterprise has one relevant institution in Beijing in average. There are a relatively small number of production sectors in Beijing, which totals 19 and accounts for $14 \%$ of the total, namely that each enterprise has only 0.6 such institution located in Beijing in average. It can thus be seen that R\&D sectors, sales and marketing sectors and headquarters are the main value chain links of electronic information enterprises in Beijing, especially R\&D sectors.

Most of headquarters of these enterprises are located in Beijing Central Business District, reaching 14\%. There are also 6 and 4 headquarters located in Zhongguancun Haidian Science Park and Electronic Technology Park in Zhongguancun Science Park. Only a very small number of them are distributed in other areas including Jinbao Street, Dongchang'an Avenue and Fuxing Road, with each accommodating one headquarters (see Table 2)[3].

Table 2 Distribution of Main Value Chain Links of Electronic Information Enterprises in Beijing (Unit: Enterprise)

\begin{tabular}{|c|c|c|c|c|}
\hline & $\begin{array}{l}\text { Headquarters } \\
\text { (Percentage) }\end{array}$ & $\begin{array}{l}\text { R\&D Sector } \\
\text { (Percentage) }\end{array}$ & $\begin{array}{l}\text { Production } \\
\text { Sector } \\
\text { (Percentage) }\end{array}$ & $\begin{array}{c}\text { Sales and } \\
\text { marketing } \\
\text { Sector } \\
\text { (Percentage) }\end{array}$ \\
\hline $\begin{array}{c}\text { Zhongguancun Haidian } \\
\text { Science Park }\end{array}$ & $6(21.43)$ & $37(61.67)$ & $2(10.53)$ & $7(23.33)$ \\
\hline $\begin{array}{c}\text { Beijing Central Business } \\
\text { District }\end{array}$ & $14(50.00)$ & $2(3.33)$ & $1(5.26)$ & $7(23.33)$ \\
\hline $\begin{array}{c}\text { Beijing } \\
\text { Economic-Technological } \\
\text { Development Area }\end{array}$ & $1(3.57)$ & $4(6.67)$ & $7(36.84)$ & $6(20.00)$ \\
\hline $\begin{array}{l}\text { Electronic Technology Park in } \\
\text { Zhongguancun Science Park }\end{array}$ & $4(14.29)$ & $9(15.00)$ & $3(15.79)$ & $7(23.33)$ \\
\hline $\begin{array}{c}\text { Beijing Tianzhu Airport } \\
\text { Economic Development Zone }\end{array}$ & $0(0.00)$ & $0(0.00)$ & $5(26.32)$ & $2(6.67)$ \\
\hline Others & $3(10.71)$ & 8(13.33) & 1（5.26） & $1(3.33)$ \\
\hline
\end{tabular}

It can be seen through analysis on Table 2 that: R\&D sectors are mainly located in Zhongguancun Haidian Science Park, up to 37; there are 9 R\&D Sectors in Electronic Technology Park in Zhongguancun Science Park; a small number of such sectors are located in Beijing Economic-Technological Development Area, Beijing Central Business District, Shijingshan Science and Technology Park, Dongchang'an avenue and Xichang'an Avenue, Zizhuyuan and areas 
surrounding Xizhimen. Production sectors are mainly locate in Beijing Economic-Technological Development Area, up to 7; there are 5 and 3 electronic technology parks in Beijing Tianzhu Airport Economic Development Zone and Zhongguancun Haidian Science Park respectively; an a small number of electronic technology parks in Zhongguancun Haidian Science Park and Beijing Central Business District. Sales and marketing sectors are mainly located in Zhongguancun Haidian Science Park, Beijing Central Business District and Electronic Technology Park in Zhongguancun Science Park, with each of them has 7 such sectors; and there are 6 sales and marketing sectors in Beijing Economic-Technological Development Area and a small number of such sectors in Beijing Tianzhu Airport Economic Development Zone.

\section{Conclusion}

Electronic information industry in Beijing and its main value chain links show an obvious trend of suburbanization and clustering. Similar to result of domestic researches on spatial distribution of high technology industries inside large cities, the trend of suburbanization, especially long-distance suburbanization, in electronic information industry in Beijing is evident and it also presents a trend of clustering in distribution. The development trend of suburbanization in electronic information industry is very obvious, for which clustering areas are mainly located in suburbs, followed by outer suburbs. Moreover, the number of people engaging in the industry in outer suburbs is increasing rapidly, especially in Daxing District and Shunyi District. At present, Beijing electronic information industry is mainly concentrated in Zhongguancun in Haidian District-areas surrounding Shangdi, Yizhuang area in Daxing District, Jiuxianqiao-Wangjing residential district in Chaoyang District and Tianzhu area in Shunyi District. Large-scale electronic information enterprises are mainly clustering in Zhongguancun Haidian Science Park, Beijing Central Business District, Electronic Technology Park in Zhongguancun Science Park, Beijing Economic-Technological Development Area and Beijing Tianzhu Airport Economic Development Zone, for which production process shows the most obvious trend of suburbanization. It is found out through researches that those areas involving the largest number of people engaging in the electronic information industry is not necessarily the clustering areas of main chain value links, especially high-end links.

\section{References}

[1] Q.C. lin, Analysis on Characteristics of Distribution of Hi-tech Industries. Human Geography, 2003, 18 (5): 38-42

[2] G.N. Tang and W.X. Xu, Research on Characteristics of Spatial and Time Evolution and Spatial Distribution of High-tech Industries in China. Economic Geography, 2004, 24 (5): 604-608.

[3] X. Jing, C.M. Guan and L. Liang et al. Preliminary Research on Choice of Locations of Communication Equipment Manufacturing Enterprises in China. Sci-tech Information Development \& Economy, 2007, 17 (1): 209-211. 